\title{
FIB-based Atom Probe Specimen Preparation of Powders
}

\author{
M. K. Miller* and K.F. Russell* \\ * Metals and Ceramics Division, Oak Ridge National Laboratory, PO Box 2008, Oak Ridge, TN \\ 37831-6136
}

Atom probe specimens are typically in the form of circular cross section needles with end radii of $30-100 \mathrm{~nm}$. The desirable taper angle should be $<\sim 5^{\circ}$ to permit acquiring a sufficiently long dataset before reaching the field evaporation voltage limit of the instrument. Due to the proximity of the aperture in the local electrode to the apex of the specimen (typically $25-50 \mu \mathrm{m}$ ), field shielding from the base of the needle is a significantly less important factor in the LEAP compared to other atom probe variants that have the field-defining aperture located some millimeters from the specimen. This insensitivity has been experimentally demonstrated as atom probe data has been obtained in the LEAP from needles fabricated from flat surfaces either by milling a moat in the surface or from multi-layer thin film specimens that were Bosch-etched and then ion milling to sharp needles [1,2].

Fine powders are difficult to prepare into atom probe needles with standard electropolishing techniques. Therefore, a FIB-based technique has been developed. In this technique, a thin layer of powder is spread on an adhesive-coated SEM stub. One particle is selected and a slot is milled, Fig 1a. A prepared $\mathrm{W}$ probe is then maneuvered into the slot and attached to the particle with platinum deposit, Fig. 1b. The particle is then lifted out from the adhesive, Fig. 1c. The probe with attached particle is transferred (ex-situ) to an atom probe stub, straightened and re-inserted into the FIB, Fig. 2. Finally, the powder particle is annularly milled to a needle-shaped atom probe specimen with a typical end radius of $\sim 50 \mathrm{~nm}$, Fig. 2. The resulting atom probe isoconcentration profile from this $\mathrm{Cu}_{47} \mathrm{Ti}_{32} \mathrm{Zr}_{11} \mathrm{Ni}_{8} \mathrm{Si}_{1}$ bulk metallic glass specimen is shown in Fig. 2. The range of particle sizes that this method can be applied to depends primarily on the method used to attach the particle to the liftout probe. The weight of the particle, the thickness and strength of the platinum deposit and milling time control the maximum size of particle, $\sim 50 \mu \mathrm{m}$, that can be used. At the lower size limit, $\sim 0.5$ $\mu \mathrm{m}$, there should be sufficient length of needle exposed not to field shield the specimen. In principle, smaller diameter particles could be fabricated into atom probe specimens by careful adaptation of the attachment method. However, the length of the dataset obtained will be limited to the exposed length of the needle. The method is applicable to fine powders of various geometries and materials.

An important consequence of the use of a gallium ion source is the implantation of gallium into the surface of the specimen and its influence on the microstructure. A typical concentration profile from the surface of a $\mathrm{Cu}_{47} \mathrm{Ti}_{32} \mathrm{Zr}_{11} \mathrm{Ni}_{8} \mathrm{Si}_{1}$ bulk metallic glass particle is shown in Fig. 3. An $\sim 20$-nm-thick gallium-enriched region is evident on the surface. The extent is consistent with SRIM simulations of $30 \mathrm{keV}$ gallium implantation. Smaller damaged regions may be obtained with lower energies. The phase separated nature of the microstructure is clearly evident beneath this damaged layer [3].

\section{References}

[1] M.K. Miller, Microsc. Microanal., 11 (suppl. 2) (2005) 808.

[2] M.K. Miller, K.F. Russell and G.B. Thompson, Ultramicroscopy, 102 (2005) 287.

[3] Research at the SHaRE User Facility was sponsored by the Division of Materials Sciences and Engineering, U. S. Department of Energy, under Contract DE-AC05-00OR22725 with UT-Battelle, LLC. 

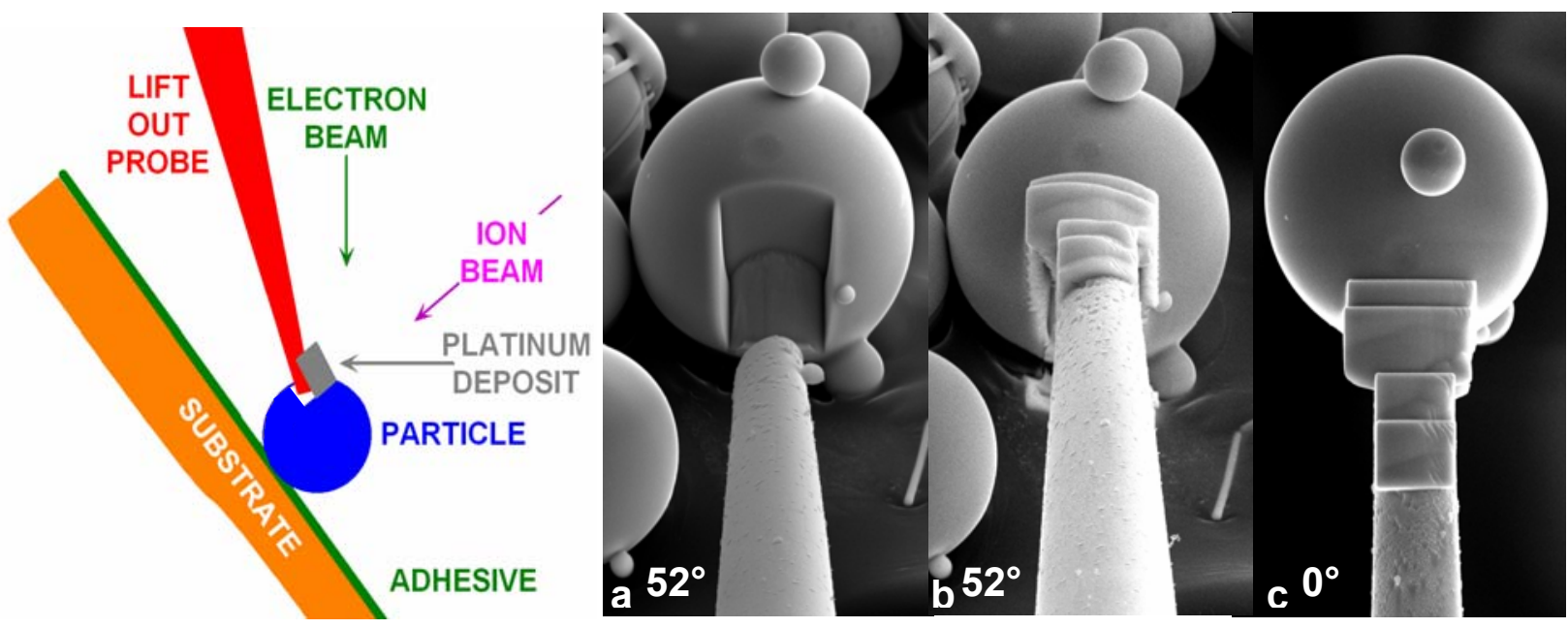

FIG. 1. A slot is milled into the base of a gas atomized bulk metallic glass particle and then a prepared $\mathrm{W}$ probe is attached to the particle with platinum deposit.
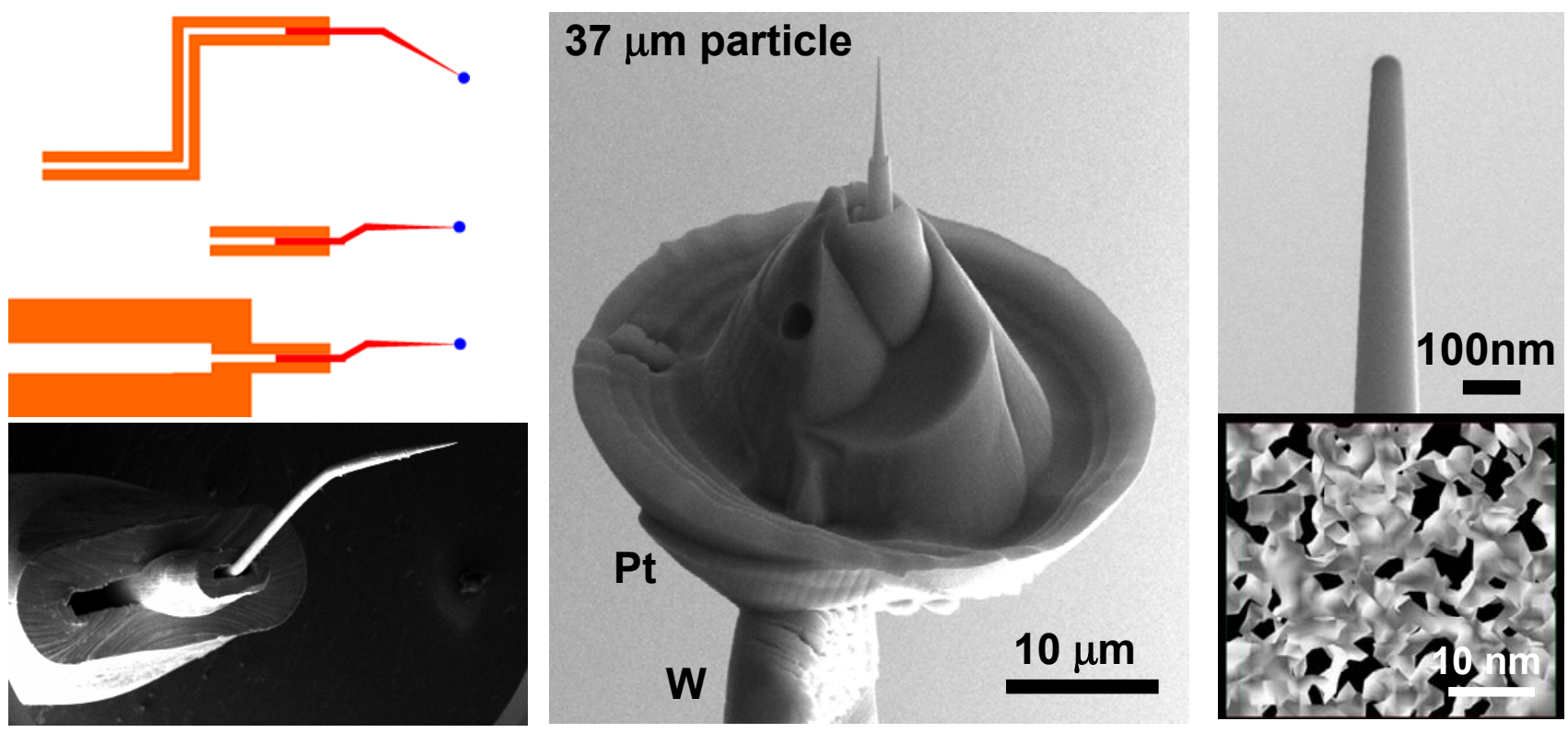

FIG. 2. The $\mathrm{W}$ probe is reoriented in the FIB and the particle is milled into a sharp needle with the use of a series of annular masks with decreasing inner diameters and decreasing milling currents. 40 at. $\% \mathrm{Cu}$ isoconcentration surface reveals interconnected structure of the phases in the BMG.
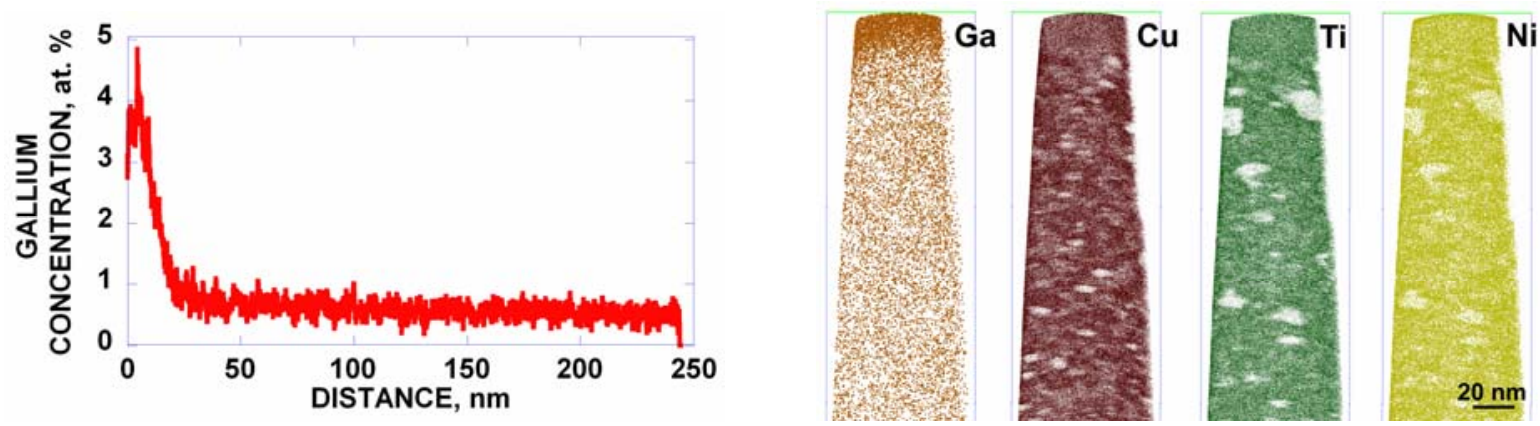

FIG. 3. Example of the extent of gallium implantation in an annealed (6h at $623 \mathrm{~K}$ ) bulk metallic glass $\mathrm{Cu}_{47} \mathrm{Ti}_{33} \mathrm{Zr}_{11} \mathrm{Ni}_{8} \mathrm{Si}_{1}$ particle. $30 \mathrm{keV}$ gallium ions. Atom maps are 5-nm-thick. 